\section{Reply to: "The possible role of anti-methicillin-resistant Staphylococcus aureus antimicrobial agents in spontaneous bacterial peritonitis"}

\author{
Marco Falcone, ${ }^{1}$ Alessandro Russo, ${ }^{1}$ \\ Manuela Merli, ${ }^{2}$ Mario Venditti ${ }^{1}$ \\ 'Department of Public Health and \\ Infectious Diseases; ${ }^{2}$ Department of \\ Clinical Medicine, Policlinico Umberto I, \\ Sapienza University of Rome, Italy
}

\section{Dear Editor,}

we thank Drs. Fiore and Andreana for their comments about our paper. ${ }^{1}$ However, we agree only in part with the majority of considerations proposed by the authors as regards to the choice to use daptomycin for the treatment of a patient with spontaneous bacterial peritonitis (SBP) due to methicillin-resistant Staphylococcus aureus (MRSA).

First of all, our patient showed at admission a severe thrombocytopenia (platelet count of $39 \times 10^{9} / \mathrm{L}$ ) and the use of linezolid (LZD) cannot be encouraged in these cases. As matter of fact, a recent study revealed significant intergroup differences in duration of LZD treatment prior to thrombocytopenia and it has been reported also within 8 days of therapy. ${ }^{2}$ Furthermore, among patients with acute or chronic liver failure a low baseline platelet count has been identified as an independent risk factor for development of severe thrombocytopenia during LZD therapy. ${ }^{3}$ The available data and the clinical judgment do not suggest to recommend LZD as first choice in patients with chronic liver failure or cirrhosis and low baseline platelet count.

Moreover, we disagree with comments about the comparison of daptomycin and LZD therapy for the treatment of vancomycin-resistant enterococci infection. Compared to LZD, it is well known that daptomycin has a reduced activity against enterococci and it is not considered a first-line option in patients with enterococcal infection. But we think that this observation is not appropriate for our case since we were treating a SBP due to MRSA. It is not necessary to review in this paper the body of evidence supporting the use of daptomycin in patients with MRSA infection. ${ }^{4}$ Furthermore, we presented a summary of data (Table 2 of our publication) ${ }^{1}$ suggesting a role for daptomycin in primary or secondary bacte- rial peritonitis. These observations seem to be confirmed by the randomized clinical trial of Piano and coworkers, who demonstrated a high efficacy of daptomycin combined to meropenem for the treatment of nosocomial SBP. 5

Finally, since we have contributed with clinical and pharmacological studies to the assessment of the better daptomycin dosage in critically ill patients, ${ }^{6-8}$ we strongly agree that a high dose of daptomycin should be considered in these situations. However, we have to outline that our patient had an acute kidney failure and daptomycin dosage should be adapted in these cases (recommendation is to use daptomycin every 48 hours if creatinine clearance is less than $35 \mathrm{~mL} / \mathrm{m}$ ). Thus the dosage we decided to administer was significantly high in the former cases.

In conclusion, there is growing evidence of an effective role of daptomycin in SBP episodes in cirrhotic patients. Considering the importance to ensure a broad-spectrum antibiotic therapy in cirrhotic patients with healthcare-associated infections, ${ }^{9,10}$ daptomycin may be considered a potential option in these cases.

\section{References}

1. Falcone M, Russo A, Pacini G, et al. Spontaneous bacterial peritonitis due to methicillin-resistant Staphylococcus aureus in a patient with cirrhosis: the potential role for daptomycin and review of the literature. Infect Dis Rep 2015;7:6127.

2. Ichie T, Suzuki D, Yasui K, et al. The association between risk factors and time of onset for thrombocytopenia in Japanese patients receiving linezolid therapy: a retrospective analysis. J Clin Pharm Ther 2015;40:279-84.

3. Zhang YM, Yu W, Zhou N, et al. High frequency of thrombocytopenia in patients with acute-on-chronic liver failure treated with linezolid. Hepatobiliary Pancreat Dis 2015;14:287-92.

4. Holland TL, Arnold C, Fowler VG Jr. Clinical management of Staphylococcus aureus bacteremia: a review. JAMA 2014;312: 1330-41.

5. Piano S, Fasolato S, Salinas F, et al. The empirical antibiotic treatment of nosocomial spontaneous bacterial peritonitis: Results of a randomized, controlled clinical trial. Hepatology 2015 Jun 18. [Epub ahead of print]
Correspondence: Marco Falcone, Department of Public Health and Infectious Diseases, Policlinico Umberto I, "Sapienza" University of Rome, Viale dell'Università 37, 00161 Rome, Italy.

Tel/Fax: + 39.06.491749.

E-mail:marco.falcone@uniroma1.it

Key words: Daptomycin; cirrhosis; methicillinresistant Staphylococcus aureus; spontaneous bacterial peritonitis.

Contributions: the authors contributed equally.

Conflict of interest: the authors declare no potential conflict of interest.

Received for publication: 9 December 2015 Accepted for publication: 9 December 2015

This work is licensed under a Creative Commons Attribution NonCommercial 3.0 License (CC BYNC 3.0).

(C) Copyright M. Falcone et al., 2015

Licensee PAGEPress, Italy

Infectious Disease Reports 2015; 7:6356

doi:10.4081/idr.2015.6356

6. Falcone M, Russo A, Venditti M, et al Considerations for higher doses of daptomycin in critically ill patients with methicillin-resistant Staphylococcus aureus bacteremia. Clin Infect Dis 2013;57:1568-76.

7. Pai MP, Russo A, Novelli A, et al. Simplified equations using two concentrations to calculate area under the curve for antimicrobials with concentration-dependent pharmacodynamics: daptomycin as a motivating example. Antimicrob Agents Chemother 2014;58:3162-7.

8. Falcone M, Russo A, Cassetta MI, et al. Variability of pharmacokinetic parameters in patients receiving different dosages of daptomycin: is therapeutic drug monitoring necessary? J Infect Chemother 2013; 19:732-9.

9. Merli M, Lucidi C, Di Gregorio V, et al. The spread of multi drug resistant infections is leading to an increase in the empirical antibiotic treatment failure in cirrhosis: a prospective survey. PLoS One 2015;10: e0127448.

10. Merli M, Lucidi C, Di Gregorio V, et al. An empirical broad spectrum antibiotic therapy in Healthcare-Associated infections improves survival in cirrhotics: aA randomized trial. Hepatology. 2015 Nov 3. [Epub ahead of print] 